\title{
Efeito de diferentes volumosos conservados na forma de silagem sobre a ingestão de alimentos e produção de leite de vacas em lactação
}

\section{Effect of different forages preserved in silage form on feed intake and milk production of lactating cows}

\author{
Elzânia Sales Pereira ${ }^{1 *}$; Alex Martins Varela de Arruda ${ }^{1}$; Ivone Yurika Mizubuti²; Augusto \\ César de Queiróz ${ }^{3}$; André Krapp ${ }^{4}$; Mirna Adriane Syperreck ${ }^{4}$; Julio César Barreto ${ }^{4}$
}

\begin{abstract}
Resumo
O objetivo do presente estudo foi avaliar o efeito de diferentes volumosos conservados na forma de silagem sobre os consumos de matéria seca, proteína bruta, matéria orgânica, extrato etéreo, fibra em detergente neutro, carboidratos totais e carboidratos não estruturais, e produção e composição do leite. Foram utilizadas 12 vacas Holandesas em lactação com produção média de $30 \mathrm{~kg}$ de leite, alimentadas com três dietas compostas pela combinação de forragem mais concentrado, a saber: (T1) $50 \%$ de silagem de milho $+25 \%$ de silagem de azevém $+25 \%$ de silagem de cevada, (T2) $50 \%$ de silagem de azevém $+25 \%$ de silagem de milho $+25 \%$ de silagem de cevada e (T3) $50 \%$ de silagem de cevada $+25 \%$ de silagem de milho $+25 \%$ de silagem de azevém. Utilizou-se delineamento em quadrado latino 3 x 3 com período extra. Os consumos de matéria seca, matéria orgânica, extrato etéreo e fibra em detergente neutro não foram influenciados pelas combinações das fontes de volumosos usados. Entretanto, o consumo de proteína bruta foi maior nos animais alimentados com a dieta 2 (T2) constituída de $50 \%$ de silagem de azevém + $25 \%$ de silagem de milho $+25 \%$ de silagem de cevada. A produção de leite corrigida, ou não, para 3,5\% de gordura; os teores de gordura e proteína, bem como a eficiência alimentar ( $\mathrm{kg}$ de leite/ $\mathrm{kg}$ de MS ingerida) não foram influenciadas pelas dietas experimentais.
\end{abstract}

Palavras-chave: Consumo, silagem de azevém, silagem de cevada, silagem de milho.

\begin{abstract}
The objective of this study was to evaluate the effect of different forages preserved in silage form on the intake of dry matter, crude protein, organic matter, ether extract, neutral detergent fiber, total carbohydrates and non structural carbohydrates, milk composition and milk production. Twelve Holstein lactating cows with average production of $30 \mathrm{~kg}$ milk were used. They were fed with three experimental diets composed by a combination of forages plus concentrate: (T1) $50 \%$ of corn silage $+25 \%$ of ryegrass silage $+25 \%$ of barley silage; (T2) $50 \%$ of ryegrass silage $+25 \%$ of corn silage $+25 \%$ of barley silage; and (T3) $50 \%$ of barley silage $+25 \%$ of corn silage $+25 \%$ of ryegrass silage. The experimental design was $3 \times 3$ Latin squares with extra period in a change over arrangement. The dry matter, organic matter, ether
\end{abstract}

\footnotetext{
1 Professores do Curso de Zootecnia da Universidade Estadual do Oeste do Paraná (UNIOESTE), Campus de Marechal Cândido Rondon / Centro de Ciências Agrárias. Rua Pernambuco, 1777, CEP:85960-000, Email: elzania@ hotmail.com

2 Professora do Departamento de Zootecnia da Universidade Estadual de Londrina (UEL)

Professor do Departamento de Zootecnia da Universidade Federal de Viçosa (UFV)

${ }^{4}$ Acadêmicos do Curso de Zootecnia da UNIOESTE, Campus de Marechal Cândido Rondon / Centro de Ciências Agrárias.

* Autor para correspondência.
} 
Pereira, E. S. et al.

extract and neutral detergent fiber intakes were not influenced by the combinations of the different forage sources in the diets. However, the crude protein intake by the animals was highest for the diet 2 (T2), that contained 50 percent of ryegrass silage $+25 \%$ of corn silage $+25 \%$ of barley silage. The corrected milk production, or not, for 3.5 percent of fat, the fat and protein milk content, and the feeding efficiency ( $\mathrm{kg}$ milk production/ $\mathrm{kg}$ DM intake) were not influenced by the experimental diets.

Key words: Barley silage, corn silage, intake, ryegras silage.

\section{Introdução}

Com a tendência de especialização do setor leiteiro, principalmente nas regiões sudeste e sul do Brasil, tem se observado aumento no número de sistemas intensivos de produção de leite, em que animais de alto potencial genético são mantidos em regime de confinamento, com a alimentação oferecida no cocho. Essa alimentação baseia-se, principalmente, em forragens conservadas como silagens e fenos, suplementadas com concentrados. O milho tem sido a forrageira de maior utilização no processo de ensilagem. Entretanto, o azevém (Lolium multiflorum L.) e a cevada (Hordeum vulgare L.) tem se mostrado como boa opção nas regiões de clima subtropical. Nestas regiões o azevém e a cevada tem sido muito explorados, em virtude de produzirem silagens de boa qualidade, com elevados rendimentos de matéria seca, e como são forrageiras de inverno, permitem rotação de cultura.

O consumo de alimento pelo animal é de fundamental importância na determinação do valor nutritivo dos alimentos, tendo em vista que o volume de nutrientes ingeridos e o desempenho animal dependem da quantidade e qualidade de alimentos consumidos. A determinação do consumo de alimento pelo animal é importante para o balanceamento adequado de suas dietas, porém, em ruminantes existem inúmeros fatores que interferem nesse consumo com intensidade de diferentes magnitude. A quantidade de alimento ingerido pode sofrer variações da ordem de 40 a 60\%, 20 a 30\%, 10 a $15 \%$ e 10 a $15 \%$, respectivamente, por efeito de fatores inerentes ao animal, ao alimento, ao ambiente e às condições de manejo (ROSELER et al.,1993). A influência do alimento sobre o consumo de matéria seca está associada a sua composição em fibra em detergente neutro (FDN), especialmente para animais em condições de alta produção, que demandam quantidades elevadas de energia em suas dietas. A formulação de dietas objetivando conter adequados níveis de energia para atender altas produções, normalmente resulta em dietas com altos níveis de grãos em detrimento da fibra (STOKES, 1997), o que pode ocasionar problemas como acidose, laminite, cetose, deslocamento de abomaso, além de redução no teor de gordura do leite (SHEARER, 1996). No entanto, dietas com altos níveis de fibra impõem aos ruminantes a necessidade de maior tempo de permanência do alimento no rúmen e ampla capacidade ruminal em acomodar material de baixa densidade para que se processe uma fermentação adequada (NUTRIENT REQUIREMENTS OF DOMESTIC ANIMALS, 1988). Nesta situação, a repleção exerce efeito significativo sobre a capacidade do animal em consumir matéria seca. A distensão física do retículo-rúmen é o principal fator limitante na ingestão de muitas forragens e dietas ricas em fibra. Porém, a presença de mecanoreceptores na parede ruminal também é responsável por esse efeito (FORBES, 1995). Assim, os animais consomem o alimento principalmente para atender às suas exigências em energia, além de outros nutrientes necessários. Entretanto, se por alguma razão a natureza do volumoso disponível restringir o consumo alimentar, limitará também o desempenho animal, cuja consequiência direta é a redução da eficiência do processo produtivo. Portanto, torna-se necessário o conhecimento dos efeitos, bem como da caracterização qualitativa e quantitativa dos alimentos comumente utilizados na alimentação dos bovinos, cujo objetivo final é a predição das respostas produtivas, para redução de custos, permitindo estratégias de manejo alimentar que resultem no incremento da produção. O objetivo deste estudo foi 
avaliar os efeitos de diferentes combinações de silagem de milho (Zea mays L.), de silagem pré-seca de azevém (Lolium multiflorum L.) e de silagem de cevada (Hordeum vulgare L.), sobre os consumos de matéria seca (MS), matéria orgânica (MO), proteína bruta $(\mathrm{PB})$, extrato etéreo (EE), carboidratos totais (CHOT), fibra em detergente neutro (FDN), carboidratos não estruturais (CNE), e produção de leite de vacas Holandesas.

\section{Material e Métodos}

O experimento foi realizado na Fazenda Capão Alto da Fundação ABC para Divulgação de Tecnologia localizada na região dos Campos Gerais - Castro PR. Foram utilizadas 12 vacas Holandesas entre a segunda e a terceira ordem de lactação, pesando em média $600 \mathrm{~kg}$ e produzindo em média 30 $\mathrm{kg}$ de leite, aos 66 dias de lactação. O delineamento experimental utilizado foi o quadrado latino $3 \mathrm{X} 3 \mathrm{com}$ período extra, no qual cada período teve duração de 16 dias e cada seqüência do experimento correspondeu a um animal. As vacas foram alojadas em baias individuais dotadas de comedouros convencionais e bebedouro adaptado. Foram avaliadas três dietas, adotando-se a relação volumoso:concentrado de 60:40, na base da matéria seca. As dietas foram constituídas de silagens de milho, azevém e cevada nas proporções que perfizeram as seguintes combinações nos tratamentos (T): $\mathrm{T} 1=50 \%$ de silagem de milho $+25 \%$ de silagem de azevém $+25 \%$ de silagem de cevada; $\mathrm{T} 2=50 \%$ de silagem de azevém $+25 \%$ de silagem de milho + $25 \%$ de silagem de cevada e $\mathrm{T} 3=50 \%$ de silagem de cevada $+25 \%$ de silagem de milho $+25 \%$ de silagem de azevém. O concentrado foi composto de caroço de algodão, polpa de citrus e uma mistura de concentrado comercial. A composição química dos alimentos e as porcentagens dos ingredientes utilizados para formulações das dietas experimentais estão apresentadas nas Tabelas 1 e 2.

Tabela 1. Composição bromatológica em matéria seca (MS, \%), matéria orgânica (MO), proteína bruta (PB), extrato etéreo, matéria mineral (MM), carboidratos totais (CHOT), carboidratos não estruturais (CNE), fibra em detergente neutro (FDN) (\% na MS), dos alimentos volumosos e concentrado utilizados nas dietas experimentais.

\begin{tabular}{lcccccccc}
\hline \multirow{2}{*}{ Ingredientes } & \multicolumn{7}{c}{ Composição bromatológica (\%MS) } \\
\cline { 2 - 9 } & MS & MO & PB & EE & MM & CHOT & CNE & FDN $^{1}$ \\
\hline Silagem de milho & 33,20 & 95,70 & 8,70 & 2,72 & 4,30 & 84,28 & 27,18 & 57,10 \\
Silagem de azevém & 42,80 & 96,11 & 14,10 & 3,79 & 3,89 & 78,22 & 30,92 & 47,30 \\
Silagem de cevada & 32,80 & 94,73 & 8,70 & 3,14 & 5,27 & 82,89 & 29,89 & 53,00 \\
Concentrado comercial & 92,00 & 87,30 & 34,10 & 2,68 & 12,70 & 50,52 & 38,52 & 12,00 \\
Polpa de citrus & 91,00 & 94,56 & 6,70 & 2,38 & 5,44 & 85,48 & 52,38 & 33,10 \\
Caroço de algodão & 92,00 & 96,12 & 20,00 & 13,60 & 3,88 & 65,52 & 6,92 & 58,60 \\
\hline
\end{tabular}

${ }^{1}$ FDN: FDN corrigida para cinzas e proteína 
Tabela 2. Porcentagem dos ingredientes (\%MS) e composição bromatológica em matéria seca (MS), matéria orgânica (MO), proteína bruta (PB), extrato étereo (EE), matéria mineral (MM), carboidratos totais (CHOT), fibra em detergente neutro corrigida para cinzas e proteina $\left(\mathrm{FDN}_{\mathrm{cp}}\right)$ das dietas experimentais

\begin{tabular}{lccc}
\hline \multirow{2}{*}{ Ingrediente } & \multicolumn{3}{c}{ Dietas experimentais } \\
\cline { 2 - 4 } & $\mathrm{T} 1$ & $\mathrm{~T} 2$ & $\mathrm{~T} 3$ \\
\hline Silagem de milho & 30,22 & 15,09 & 15,09 \\
Silagem de azevém & 15,10 & 30,18 & 15,09 \\
Silagem de cevada & 15,10 & 15,09 & 30,18 \\
Polpa de cítrus & 10,08 & 7,85 & 10,05 \\
Caroço de algodão & 7,85 & 10,06 & 7,84 \\
Concentrado comercial & 21,65 & 21,12 & 21,12 \\
\hline
\end{tabular}

\begin{tabular}{lccc} 
Nutrientes & \multicolumn{3}{c}{ Composição bromatológica } \\
(\%) & \\
\hline MS (\%) & 57,76 & 58,70 & 57,15 \\
MO & 93,72 & 93,27 & 92,98 \\
PB & 15,70 & 16,68 & 15,50 \\
EE $^{2}$ & 3,76 & 4,15 & 3,80 \\
CHOT & 74,50 & 72,80 & 73,91 \\
FDN $_{\mathrm{CP}}$ & 43,00 & 42,00 & 42,18 \\
\hline
\end{tabular}

${ }^{\mathrm{T} 1} 50 \%$ de silagem de milho, $25 \%$ de silagem pré-seca de azevem e $25 \%$ de silagem de cevada.

${ }^{\mathrm{T}} 250 \%$ de silagem pré-seca de azevem, $25 \%$ de silagem de milho e $25 \%$ de silagem de cevada.

${ }^{\text {T3 }} 50 \%$ de silagem de cevada, $25 \%$ de silagem pré-seca de azevem e $25 \%$ de silagem de milho.

Os quatro períodos experimentais tiveram duração de 16 dias cada um, sendo 10 dias de adaptação à dieta, e seis dias para mensuração do consumo e produção de leite. Os animais foram pesados no início e no final de cada período experimental. A dieta total foi fornecida à vontade, duas vezes ao dia, as 6:30 e as 13:30 horas, e as sobras foram recolhidas e pesadas todos os dias, para determinação do consumo diário. A quantidade de dieta fornecida foi calculada de modo a permitir aproximadamente $10 \%$ de sobras. A água foi fornecida à vontade. Após término dos períodos de coletas, as amostras de fezes, silagens, concentrado e sobras foram secas em estufa de ventilação forçada a $55^{\circ} \mathrm{C}$ por 72 horas e moídas em moinho tipo Willey em peneiras de $1 \mathrm{~mm}$. Em seguida, foram homogeneizadas para confecção de amostras compostas por animal, com base no peso seco, para cada período.

As vacas foram ordenhadas três vezes ao dia, diariamente, sendo suas produções registradas individualmente. As amostras de leite foram coletadas nas três ordenhas do $10^{\circ}$ ao $15^{\circ}$ dia de cada período experimental e submetidas a análises laboratoriais para determinar os teores de gordura e proteína, conforme Pregnolatto e Pregnollato (1985). A produção de leite foi corrigida para 3,5\% de gordura (PLC) segundo Sklan et al. (1992), utilizando-se a seguinte fórmula:

$$
\text { PLC }=(0,432+0,1625 \times \mathrm{G}) \times \mathrm{Kg} \text { de leite, }
$$

onde: $\mathrm{G}=\%$ de Gordura do leite.

A eficiência alimentar foi calculada para cada animal, dividindo-se a produção média de leite pela ingestão de matéria seca. Foram realizadas amostras compostas das silagens fornecidas e dos concentrados, por tratamento; e das sobras, por animal em cada período. Todas estas amostras foram devidamente armazenadas a $-5^{\circ} \mathrm{C}$, e posteriormente moídas em moinho com peneira de $1 \mathrm{~mm}$ e submetidas às análises laboratoriais. Os alimentos foram analisados para matéria seca (MS), matéria mineral $(\mathrm{MM})$, matéria orgânica (MO), proteína bruta (PB) e extrato etéreo (EE) seguindo os procedimentos descritos na Association of Official Analytical Chemists (1990); e fibra em detergente neutro (FDN) e ácido (FDA), conforme Van Soest et al. (1991). Os carboidratos totais foram determinados pela seguinte expressão: $\mathrm{CHOT}=100-(\% \mathrm{~PB}+\% \mathrm{EE}+$ $\% \mathrm{MM}$ ), segundo Sniffen et al. (1992). Os carboidratos não estruturais $\left(A+B_{1}\right)$ foram determinados pela seguinte expressão: $\mathrm{CNE}=100$ - 
$\left(\% \mathrm{~PB}+\% \mathrm{EE}+\% \mathrm{FDN}_{\mathrm{CP}}+\mathrm{MM}\right)$, em que $\mathrm{FDN}_{\mathrm{CP}}$ eqüivale a parede celular corrigida para cinzas e proteínas. A fração $\mathrm{C}$ foi obtida através do resíduo indigestível após 96 horas de incubação com líquido ruminal; a fração $\mathrm{B}_{2}$ foi determinada por diferença entre 100 menos a FDN remanescente após 96 horas de incubação.

Procurou-se ainda determinar o perfil do tamanho das partículas da silagem de milho, da silagem préseca de azevém e da silagem de cevada utilizandose o separador de partículas modelo Penn State de acordo com a metodologia proposta por Heinrichs (1996) e Lammers, Buckmaster e Heinrichs (1996), em consonância com os procedimentos sugeridos pela American Dairy Science Association (1970). Aproximadamente cem gramas de cada uma das silagens trituradas foram pesadas em balança eletrônica e colocadas sobre o separador de partículas, constituído de duas peneiras (topo e meio) e uma bandeja do fundo. As três caixas plásticas foram empilhadas uma sobre a outra, ficando na parte superior a peneira de maior malha, no meio a peneira de menor malha e na parte inferior a bandeja coletora. Os diâmetros dos furos das peneiras foram de 19 $\mathrm{mm}(12,2 \mathrm{~mm}$ de espessura) e $8 \mathrm{~mm}(6,4 \mathrm{~mm}$ de espessura), para as peneiras do topo e do meio, respectivamente, dividindo a amostra em três porções: material maior que $19 \mathrm{~mm}$, sobre a peneira do topo, material entre 19 e $8 \mathrm{~mm}$, sobre a peneira do meio, e material menor que $8 \mathrm{~mm}$, sobre a bandeja do fundo. Em uma superfície plana, a pilha foi agitada em cada direção, por cinco vezes. Depois de agitada em um sentido, a pilha foi rotacionada em um quarto de giro, sendo esse processo repetido por mais sete vezes, totalizando portanto, dois giros completos. Após esse procedimento, o material remanescente em cada peneira e na bandeja coletora foi pesado em balança eletrônica e, dessa forma, determinado o perfil das fibras das silagens.

Os dados de consumo e produção de leite foram avaliados por meio de análises de variância e regressão, utilizando-se o programa SAEG - Sistema de Análises
Estatísticas e Genéticas (UNIVERSIDADE FEDERAL DE VIÇOSA, 1995).

\section{Resultados e Discussão}

Os resultados sobre o perfil de distribuição das partículas das silagens estão apresentados na Tabela 3. Os tamanhos de partículas maiores que $19 \mathrm{~mm}$ foram: 18,$37 ; 57,45$ e $22,92 \%$; entre 19 e $8 \mathrm{~mm}$ foram: 48,$98 ; 27,66$ e $25,00 \%$; e menor que $8 \mathrm{~mm}$ foram: 32,$65 ; 14,89$ e $52,08 \%$, respectivamente, para as combinações de silagens do T1, T2 e T3. As combinações de silagens do T1 e T3 apresentaram um perfil do tamanho de partículas mais próximo do recomendado para uma ótima efetividade da fibra, para as peneiras de topo, meio e bandeja do fundo, respectivamente. Allen (1997), relatou que ruminantes necessitam de fibra efetiva em suas dietas para atender suas exigências em fibra e maximizar a produção e manutenção da estabilidade ruminal. A silagem pré-seca de azevém apresentou um alto percentual de tamanho de partículas maior que 19 $\mathrm{mm}$, o que pode implicar em alta efetividade da fibra, mas também em alto tempo despendido na ruminação e menor tempo de passagem. Entretanto, a distribuição de tamanho de partícula abaixo de $8 \mathrm{~mm}$ para as silagens de cevada $(52,08 \%)$ e de milho $(32,65 \%)$, pode promover alterações na eficiência de mastigação e, consequentemente, na produção de saliva e manutenção do $\mathrm{pH}$ ruminal. Associado a isso, o percentual de partículas finamente moídas, com menor ponto de adesão, pode inibir o crescimento microbiano pela passagem, antes que o processo de colonização se instale (VAN SOEST, 1994). Assim, quanto menor o tamanho da partícula do substrato que os microrganismos estão aderidos, menores serão o número e os pontos disponíveis para adesão, dificultando o processo de colonização, com conseqüente queda na digestibilidade do substrato. Poppi, Hendricksen e Minson (1985) propuseram a teoria do tamanho crítico de partículas, descrevendo que a retenção no rúmen-retículo é dependente do tamanho dessas partículas. Sauvant (1997), informou 
que a proporção de partículas de determinado tamanho obtida do bolo alimentar ingerido guarda uma estreita correlação positiva com a mesma proporção medida em uma determinada dieta e sugeriu que o fluxo de partículas é dependente do tamanho da partícula, da parede celular e da fração indigestível da dieta. A efetividade física da fibra é relacionada a um grande número de fatores, tais como: tamanho de partícula, ingestão de matéria seca, forma da partícula, fragilidade, umidade, tipo de preservação, e a razão tempo de ingestão e tempo de ruminação. Portanto, um método laboratorial para estimar o fator de efetividade física seria mais acurado se uma função fosse derivada, e que se considerasse cada uma dessas variáveis. À medida que a ingestão aumenta, a quantidade de movimentos mastigatórios por unidade de MS é reduzida, provavelmente porque existe um tempo máximo que $\mathrm{o}$ animal pode mastigar por dia.

Tabela 3. Perfil de distribuição de partículas das silagens (\%)

\begin{tabular}{cccc}
\hline \multirow{2}{*}{ Tamanho } & \multicolumn{3}{c}{ Dietas experimentais } \\
\cline { 2 - 4 } & $\mathrm{T} 1$ & $\mathrm{~T} 2$ & $\mathrm{~T} 3$ \\
\hline$>19 \mathrm{~mm}$ & 18,37 & 57,45 & 22,92 \\
& & & \\
entre 8 e 19mm & 48,98 & 27,66 & 25,00 \\
Acumulado & & & \\
$\quad>8 \mathrm{~mm}$ & 67,35 & 85,11 & 47,92 \\
Abaixo de 8mm & 32,65 & 14,89 & 52,08 \\
Acumulado total & 100,00 & 100,00 & 100,00 \\
\hline
\end{tabular}

${ }^{\text {T1 }} 50 \%$ de silagem de milho, $25 \%$ de silagem pré-seca de azevem e $25 \%$ de silagem de cevada.

${ }^{\mathrm{T} 2} 50 \%$ de silagem pré-seca de azevem, $25 \%$ de silagem de milho e $25 \%$ de silagem de cevada.

${ }^{\text {т3 }} 50 \%$ de silagem de cevada, $25 \%$ de silagem pré-seca de azevem e $25 \%$ de silagem de milho.

Os consumos de MS, MO, EE e FDN (Tabela $_{\text {c }}$ 4) expressos em kg/dia não foram influenciados pelos tipos dietéticos de fibra, oriundos dos tratamentos:
$\mathrm{T} 1$ (50\% de silagem de milho), T2 (50\% de silagem pré-seca de azevém) e T3 (50\% silagem de cevada). Por outro lado, o T2 que continha dieta composta de $50 \%$ de silagem pré-seca de azevém, promoveu maior consumo de $\mathrm{PB}(\mathrm{P}<0,05)$ do que o T1 e T3, que não diferiram entre si.

Tabela 4. Consumos médios de matéria seca (MS), matéria orgânica (MO), proteína bruta (PB), extrato etéreo (EE), fibra em detergente neutro corrigida para cinzas e proteína $\left(\mathrm{FDN}_{\mathrm{cp}}\right)$, carboidratos totais (CHOT) e carboidratos não estruturais (CNE) expressos em diferentes formas e respectivos coeficientes de variação $(\mathrm{CV})$ das dietas experimentais.

\begin{tabular}{|c|c|c|c|c|}
\hline \multirow{2}{*}{ Nutrientes } & \multicolumn{4}{|c|}{ Dietas } \\
\hline & $\mathrm{T} 1$ & $\mathrm{~T} 2$ & T3 & $\mathrm{CV}(\%)$ \\
\hline \multicolumn{5}{|c|}{$\mathrm{Kg} / \mathrm{dia}$} \\
\hline MS & $21,93^{\mathrm{a}}$ & $21,91^{\mathrm{a}}$ & $21,49^{\mathrm{a}}$ & 3,79 \\
\hline MO & $20,33^{\mathrm{a}}$ & $20,13^{\mathrm{a}}$ & $19,89^{\mathrm{a}}$ & 3,77 \\
\hline PB & $3,44^{\mathrm{b}}$ & $3,78^{\mathrm{a}}$ & $3,44^{\mathrm{b}}$ & 5,26 \\
\hline $\mathrm{EE}$ & $0,82^{\mathrm{a}}$ & $0,87^{\mathrm{a}}$ & $0,83^{\mathrm{a}}$ & 8,37 \\
\hline $\mathrm{FDN}_{\mathrm{cp}}$ & $8,95^{\mathrm{a}}$ & $8,71^{\mathrm{a}}$ & $8,69^{\mathrm{a}}$ & 4,42 \\
\hline CHOT & $16,06^{\mathrm{a}}$ & $15,48^{\mathrm{b}}$ & $15,61^{\mathrm{ab}}$ & 3,88 \\
\hline $\mathrm{CNE}$ & $7,11^{\mathrm{a}}$ & $6,77^{\mathrm{b}}$ & $6,92^{\mathrm{ab}}$ & 4,02 \\
\hline \multicolumn{5}{|c|}{ \% PV } \\
\hline MS & $3,88^{\mathrm{ab}}$ & $3,96^{\mathrm{a}}$ & $3,79^{\mathrm{b}}$ & 4,13 \\
\hline $\mathrm{FDN}_{\mathrm{cp}}$ & $1,58^{\mathrm{a}}$ & $1,57^{\mathrm{a}}$ & $1,53^{\mathrm{a}}$ & 4,79 \\
\hline CHOT & $2,84^{\mathrm{a}}$ & $2,80^{\mathrm{a}}$ & $2,75^{\mathrm{a}}$ & 4,28 \\
\hline $\mathrm{CNE}$ & $1,26^{\mathrm{a}}$ & $1,23^{\mathrm{a}}$ & $1,22^{\mathrm{a}}$ & 4,45 \\
\hline \multicolumn{5}{|c|}{$\left(\mathrm{g} / \mathrm{Kg}^{\mathbf{0}, 75}\right)$} \\
\hline MS & $179,43^{\mathrm{a}}$ & $192,05^{\mathrm{a}}$ & $184,95^{\mathrm{a}}$ & 13,44 \\
\hline $\mathrm{FDN}_{\mathrm{cp}}$ & $1,58^{\mathrm{a}}$ & $1,57^{\mathrm{a}}$ & $1,53^{\mathrm{a}}$ & 4,41 \\
\hline
\end{tabular}

${ }^{\text {T1 }} 50 \%$ de silagem de milho, $25 \%$ de silagem pré-seca de azevem e $25 \%$ de silagem de cevada.

${ }^{\mathrm{T} 2} 50 \%$ de silagem pré-seca de azevem, $25 \%$ de silagem de milho e $25 \%$ de silagem de cevada.

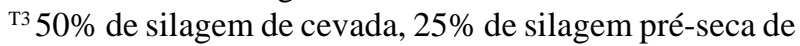
azevem e $25 \%$ de silagem de milho.

Médias seguidas de letras diferentes na linha diferem entre si $(\mathrm{P}<0,05)$ pelo teste de Tukey 
Quando o consumo de MS foi expresso em \%PV, observou-se maiores consumos pelos animais submetidos às dietas T2 (50\% de silagem de azevém) $(3,96 \%)$ e T1 (50\% de silagem de milho) $(3,88 \%)$ e menores consumos para os animais alimentados com dieta T3 (50\% de silagem de cevada) (3,79\%). Esses consumos relativos ao peso vivo dos animais estão dentro da faixa considerada normal para essa categoria animal, nas condições fisiológicas e de peso em que se encontravam, segundo os padrões de alimentação para gado leiteiro (NUTRIENT REQUIREMENTS OF DOMESTIC ANIMALS, 1988; AGRICULTURAL AND FOOD RESEARCH COUNCIL, 1993).

O consumo total de FDN expresso em $\mathrm{kg} / \mathrm{dia}$ variou de 8,95 nos animais recebendo dietas $\mathrm{T} 1$ (50\% de silagem de milho) a $8,69 \mathrm{~kg} / \mathrm{dia}$ nos animais que receberam dietas $\mathrm{T} 3$ (50\% de silagem de cevada), o que correspondeu a 1,58 e $1,53 \%$ do PV, respectivamente. Estes valores foram superiores à ingestão de FDN da ordem de 1,2 \% do peso vivo, citado por Mertens $(1996,1997)$, como limitante para o consumo de MS. Admitiu-se, portanto, que o consumo não foi controlado pela demanda de energia, pois os níveis de consumo de FDN foram superiores a esse valor. Uma vez que as dietas foram isonutricionais, os níveis de energia e de FDN não poderiam ter influência sobre o consumo de matéria seca e, desta forma, não poderiam ter reflexos sobre o consumo de nutrientes, indicando que esses resultados podem, de certa forma, ser considerados normais. Entretanto, os consumos de ração e de seus componentes nutricionais foram testados tendo em vista que o perfil de fibra da dieta poderia ter reflexos sobre o tempo médio de retenção da digesta e, assim, ter significativo efeito sobre o consumo de ração. Os consumos de nutrientes observados para todos os tratamentos foram suficientes para garantir um aporte nutricional adequado para sustentar a produção de leite e manter o escore corporal dos animais dentro da faixa desejada para o "status" fisiológico em que os animais se encontravam.
Os valores médios da produção, eficiência produtiva e composição do leite e respectivos coeficientes de variação estão demonstrados na Tabela 5.

Tabela 5. Valores médios de produção de leite corrigida (PLC) ou não (PL) para 3,5\% de gordura $(\mathrm{G})$ e proteína bruta (PB) do leite, e eficiência alimentar ( $\mathrm{kg}$ leite $/ \mathrm{kg}$ de MS) em função das dietas experimentais.

\begin{tabular}{ccccc}
\hline \multirow{2}{*}{ Variáveis } & \multicolumn{4}{c}{ Dietas experimentais } \\
\cline { 2 - 5 } & $\mathrm{T} 1$ & $\mathrm{~T} 2$ & $\mathrm{~T} 3$ & $\mathrm{CV}(\%)$ \\
\hline PL (Kg/dia) & $30,16^{\mathrm{a}}$ & $30,40^{\mathrm{a}}$ & $29,83^{\mathrm{a}}$ & 4,71 \\
PLC ((kg/dia) & $28,95^{\mathrm{a}}$ & $28,95^{\mathrm{a}}$ & $28,40^{\mathrm{a}}$ & 4,69 \\
Eficiência & $1,37^{\mathrm{a}}$ & $1,38^{\mathrm{a}}$ & $1,34^{\mathrm{a}}$ & 4,05 \\
Gordura (\%) & $3,30^{\mathrm{a}}$ & $3,21^{\mathrm{a}}$ & $3,24^{\mathrm{a}}$ & 5,81 \\
Gordura (g/dia) & $979,60^{\mathrm{a}}$ & $973,10^{\mathrm{a}}$ & $954,70^{\mathrm{a}}$ & 5,92 \\
PB (\%) & $2,75^{\mathrm{a}}$ & $2,74^{\mathrm{a}}$ & $2,76^{\mathrm{a}}$ & 2,06 \\
PB (g/dia) & $825,40^{\mathrm{a}}$ & $829,60^{\mathrm{a}}$ & $816,50^{\mathrm{a}}$ & 4,89
\end{tabular}

${ }^{\mathrm{T} 1} 50 \%$ de silagem de milho, $25 \%$ de silagem pré-seca de azevem e $25 \%$ de silagem de cevada.

${ }^{\mathrm{T} 2} 50 \%$ de silagem pré-seca de azevem, $25 \%$ de silagem de milho e $25 \%$ de silagem de cevada.

${ }^{\text {T3 }} 50 \%$ de silagem de cevada, $25 \%$ de silagem pré-seca de azevem e $25 \%$ de silagem de milho.

Médias seguidas de letras diferentes na linha diferem entre si $(\mathrm{P}<0,05)$ pelo teste de Tukey

Não foram detectadas diferenças significativas dos diferentes tipos de dieta sobre a produção de leite, registrando-se produções de 30,16; 30,40 e 29,83 kg/dia para as dietas T1 (50\% de silagem de milho), T2 (50\% de silagem pré-seca de azevém) e T3 (50\% de silagem de cevada), respectivamente. Isso provavelmente ocorreu por não ter havido diferença nos consumos dos nutrientes exceto para PB e CHOT.

Observou-se que os teores de gordura do leite, expressos em \% e em g/dia não foram influenciados pelas dietas experimentais, apresentando valores médios de 3,25\% e 969,13 g/dia, respectivamente. 
Com relação a proteína do leite em \% e g/dia não se detectou diferenças significativas entre as dietas experimentais, obtendo-se valores de 2,75; $2,74 \mathrm{e}$ 2,76\% para dietas $\mathrm{T} 1$ (50\% de silagem de milho), $\mathrm{T} 2$ (50\% de silagem de azevém ) e T3 (50\% de silagem de cevada), respectivamente. Segundo Jonker, Kohn e Erdman (1999), dietas com baixos níveis de energia e de proteínas degradáveis no rúmen em relação às exigências dos animais podem resultar em decréscimo na produção de leite e, consequentemente, da secreção do mesmo. Por outro lado, Roseler et al. (1993) relataram que a produção de proteína do leite foi positivamente correlacionada à produção de leite. Os resultados das análises físicoquímicas do leite encontrados neste trabalho (Tabela 5) estão dentro de valores recomendados pelo Regulamento de Inspeção Industrial e Sanitária de Produtos de Origem Animal (CEARÁ, 2003).

\section{Conclusões}

O consumo de proteina bruta pelos animais foi maior para a dieta constituída de $50 \%$ de silagem de azevém $+25 \%$ de silagem de milho $+25 \%$ de silagem de cevada.

As combinações das fontes de volumosos usados nas dietas não influenciaram as características de produção de leite, porcentagem de gordura e proteína do leite, bem como a eficiência alimentar.

As combinações de volumosos podem ser utilizadas sem causar prejuízo às características de consumo e de produção de leite dos animais.

\section{Referências}

AGRICULTURAL AND FOOD RESEARCH COUNCIL. Energy and protein requirements of ruminants. Wallingford: Cab International, 1993.

ALLEN, M. S. Relationship between fermentation acid production in the rumen and the requirement for physically effective fiber. Journal of Dairy Science, Savoy, v.80, n.7, p.1447-1462, 1997.
AMERICAN DAIRY SCIENCE ASSOCIATION. A report: committee on classification of particle size in feedstuffs. Journal of Dairy Science, Savoy, v.53, n.5, p.689-690, 1970.

ASSOCIATION OF OFFICIAL ANALYTICAL CHEMISTS. Official Methods of Analysis of the Association of analytical chemists. 15.ed. Arlington: The Association, 1990. v.2.

CEARA. Secretaria da Agricultura e Pecuária. Regulamento de inspeção industrial e sanitária de produtos de origem animal. Disponivel em: <http:// www.Seagri.ce.gov.br/InsProdOrAni.htm>. Acesso em: 18 out. 2003.

FORBES, J. M. Physical limitation of feed intake in ruminants and its interaction with other factors affecting intake. In: ENGELHARDT, W.; LEONHARD-MAREK, S.; BREVES, G.; GIESECKE, D. (Ed.). Ruminant physiology: digestion, metabolism, growth and reproduction. Stuttgart: Enke Veralg, 1995. p.217-232.

HEINRICHS, J. Evaluating particle size of forages and TMRs using the Penn State Particle size separator. Penn State: College of Agricultural Sciences at Penn State University, 1996.

JONKER, J. S.; KOHN, R. A.; ERDMAN, R. A. Milk urea nitrogen target concentrations for lactating dairy cows fed according to National Research Council recommendations. Journal of Dairy Science, Savoy, v.82, n.6, p.1261-1273, 1999.

LAMMERS, B. P.; BUCKMASTER, D. R.; HEINRICHS, A .J. A simple method for analyses of particle size of forage and total mixed rations. Journal of Dairy Science, Savoy, v.79, n.5, p.922-928, 1996.

MERTENS, D. R. Creating a system for meeting the fiber requirements of dairy cows. Journal of Dairy Science, Savoy, v.80, n.7, p.1463-1481, 1997.

Using fiber and carbohydrate analyses to formulate dairy rations. In: INFORMATIONAL CONFERENCE WITH DAIRY AND FORAGE INDUSTRIES, 1996, Virginia. Proceedings... Virgínia: Dairy Forage Research Center, 1996. p.81-92.

NUTRIENT REQUIREMENTS OF DOMESTIC ANIMALS. Nutrient requirements of dairy cattle. $7^{\text {th }} \mathrm{ed}$. Washington, 1988.

POPPI, D. P.; HENDRICKSEN, R. E.; MINSON, D. J. The relative resistance to escape of leaf and steam particle from the rumen of cattle and sheep. Journal of Agricultural Science, Cambridge, v.105, n.1, p.9, 1985.

PREGNOLATTO ,W.; PREGNOLATTO,N. P. Normas analíticas do Instituto Adolfo Lutz: métodos químicos e físicos para análise de alimentos. 3.ed. São Paulo: Instituto Adolfo Lutz, 1985. 
ROSELER, D. K.; FOX, D. G.; CHASE, L. E.; STONE, W. C. Feed intake prediction and diagnosis in dairy cows. In: CORNELL NUTRITION CONFERENCE FOR FEED MANUFACTURERS, 1993, Rochester. Proceedings... Ithaca: Cornell University, 1993. p.216-226.

SAUVANT, D. Rumen mathematical modeling. In: HOBSON, P. N.; STEWART,C.S. (Ed.). The rumen microbial ecosystem. 2.ed. London: Blackie Academic \& professional, 1997. p.685-708.

SHEARER, J. K. Lameness in dairy cattle: laminitis, claw disease, digital dermatitis, and foot root. Journal of Dairy Science, Savoy, v.79, p.189, 1996.

SKLAN, D.; ASHKENAZI, R.; BRAUNT, A.; DEVORIN, A.; TABORI, K. Fatty acids, calcium soaps of fatty acids and cottonseeds fed to hight yielding cows. Journal of Dairy Science, Savoy, v.75, n.9, p.2463-2472, 1992.

SNIFFEN, C. J.; O'CONNOR, J. D.; VAN SOEST, P.J.; FOX, D. G.; RUSSELL, J. B. A net carbohydrate and protein system for evaluating cattle diets: II. Carbohydrate and Protein Availability. Journal of Animal Science., Savoy, v.70, n.11, p.3562-3577, 1992.

STOKES, S. R. Particle size and ration uniformity: is it important to the cow? In: WESTERN CANADIAN DAIRY SEMINAR, 1997, Alberta. Proceedings... Stephenville: A\&M University, 1997. p.1-10.

UNIVERSIDADE FEDERAL DE VIÇOSA. Sistema de análises estatísticas e genética - SAEG. Viçosa :UFV, 1995. Apostila mimeo.

VAN SOEST, P. J.; ROBERTSON, J. B.; LEWIS, B. A. Methods for dietary fiber, neutral detergent fiber, and nonstarch polysaccharides in relation to animal nutrition. Journal of Dairy Science, Savoy, v.74, n.10, p.3583-3597, 1991.

VAN SOEST, P.J. Nutritional ecology of the ruminant. 2.ed. Ithaca: Cornell University Press, 1994. 
